\title{
Selective reporting in clinical trials - an examination of discrepancy rates in pre-specified and reported outcomes in articles submitted to the BMJ
}

\author{
Jennifer Weston ${ }^{1}$, Kerry Dwan', Douglas Altman², Mike Clarke 3 , Carrol Gamble1, Trish Groves ${ }^{4}$, Sara Schroter ${ }^{4}$, \\ Paula Williamson', Jamie Kirkham ${ }^{1 *}$
}

From 3rd International Clinical Trials Methodology Conference

Glasgow, UK. 16-17 November 2015

\section{Background}

Adding, omitting or changing pre-specified outcomes can result in bias because it increases the potential for unacknowledged or post-hoc revisions of the planned analyses. Journals have adopted initiatives such as requiring the prospective registration of trials to promote the transparency of reporting in clinical trials.

\section{Methods}

A review of all 3156 articles submitted to The BMJ between September 2013 and July 2014. Trial registry entries, protocols and trial reports of randomised controlled trials published by The BMJ and a random sample of those rejected were reviewed to determine the frequency and type of outcome discrepancies between pre-specified and reported outcomes. Editorial, peer reviewer comments and author responses were also examined to ascertain any reasons for discrepancies.

\section{Results}

In the study period, The BMJ received 311 trial manuscripts, 21 of which were published by the journal. In trials published by The BMJ, 22\% (75/339) of the pre-specified outcomes were not reported and 8\% (25/297) of reported outcomes were not pre-specified. Discrepancy rates for rejected articles were similar. The majority of reasons provided by authors for outcome discrepancies were not bias related.

\section{Conclusions}

Mandating the prospective registration of a trial and requesting that a protocol be uploaded when submitting a trial article to a journal has the potential to promote transparency and safeguard the evidence base against outcome reporting biases as a result of outcome discrepancies. Further guidance is needed with regards to documenting reasons for outcome discrepancies and making these reasons available.

\section{Authors' details \\ 'University of Liverpool, Liverpool, UK. ${ }^{2}$ University of Oxford, Oxford, UK. ${ }^{3}$ Queen's University Belfast, Belfast, UK. ${ }^{4}$ The BMJ, London, UK.}

Published: 16 November 2015

doi:10.1186/1745-6215-16-S2-072

Cite this article as: Weston et al: Selective reporting in clinical trials - an examination of discrepancy rates in pre-specified and reported outcomes in articles submitted to the BMJ. Trials 2015 16(Suppl 2):072.

Submit your next manuscript to BioMed Central and take full advantage of:

- Convenient online submission

- Thorough peer review

- No space constraints or color figure charges

- Immediate publication on acceptance

- Inclusion in PubMed, CAS, Scopus and Google Scholar

- Research which is freely available for redistribution

Submit your manuscript at www.biomedcentral.com/submit
() Biomed Central

"University of Liverpool, Liverpool, UK

Full list of author information is available at the end of the article 